\title{
Ruminantes de memórias: sentimentos, experiências e silêncios deliberados
}

\author{
Ruminants of memories: feelings, experiences and \\ deliberate silences
}

Rumiantes de memorias: sentimientos, experiencias y silencios deliberados

João Carlos Tedesco

A luta do homem contra o poder torna-se a luta da memória contra o esquecimento.

(Kundera, M. Il libro del riso e dell'oblio).

\section{Resumo}

O texto analisa horizontes subjetivos da memória bem como o seu uso político; demonstra que lembrança e esquecimento são indissociáveis e indissolúveis, estão ligados entre si; podem servir para múltiplas intenções e funções. Esquecimentos podem ser deliberados, como também lembranças passam a ser seletivizadas. Daremos ênfase à questão dos ressentimentos individuais e coletivos demonstrando que há sentimentos de memória que são profundos, intensos e difíceis de apagar. Nesse sentido, tanto a lembrança, quanto o esquecimento são dinâmicas que servem para ajustar o passado com o presente.

Palavras-chave: Memória. Ressentimento. Poder político.

\section{Introdução}

A memória humana é uma realidade complexa e produto de múltiplas interveniências, intencionalidades, condições e situações temporais. A mesma expressa capacidade de armazenar, de conservar traços de experiências passadas, sentidas, vividas e observadas, de ter acesso a elas, posteriormente, pelo horizonte da lembrança, ou, então, evitá-la por meio de esquecimento

Doutor em Ciências Sociais pela Universidade de Campinas. Professor titular da Universidade de Passo Fundo, nas áreas de Ciências Sociais e no PPG-História.

Recebido em: 22/02/2013 - Aprovado em: 14/06/2013 http://dx.doi.org/10.5335/hdtv.13n.2.3724 
auto/alter determinados. Nesse sentido, a memória pode também, deliberadamente, desenvolver o desejo de conservação e de silêncio, pela possibilidade e/ou temor de esquecimento ou para servir de referência ao convívio social (ANSART, 2002; POLLAK, 1989).

Os sentimentos de memória podem ser muito profundos e intensos; desse modo, quanto mais significativos, mais difíceis de serem apagados e não lembrados. Biólogos dizem-nos que no nosso cérebro a memória funciona em camadas sobrepostas, uma lembrança vai cobrindo a outra, mas sem anulá-la. Intensidades de experiências e significados resistem mais à sobreposição de outras lembranças, por isso que o alimento para a memória é a capacidade de consciência e de lembrança de fatos e (situ)ações que marcam a vida (IZQUIERDO, 2004).

Não podemos esquecer que a memória, em suas dimensões do esquecimento e da recordação, está impregnada na dimensão do sensível e da subjetividade (GALZERANI, 2008), fundadas, muitas vezes, em sentimentos negativos, de perda, de raiva, de humilhação que ruminam a consciência e a experiência do vivido (HUYSSEN, 2000). Para Proust (1981), que fez um belo estudo fenomenológico sobre os passados significativos na memória, tentando entender os processos que objetivam buscar o tempo perdido e o sentimento de perda, em geral, vividos na infância, em "outro tempo", como ele diz, carrega sentidos profundos e tornam a consciência e a sensibilidade da passagem do tempo na dimensão da perda e/ou da transformação. Para o autor, a dificuldade é saber lidar com o fantasma do esquecimento, da consciência de que o mundo muda e, temos necessidade de acompanhar esse processo, em especial, as sensibilidades sociais e pessoais do presente. $\mathrm{O}$ autor diz que os objetos de referência vão se desgastando como se corroem nossas vidas, nossa existência; retornar a ambas não é nada fácil, quando não impossível, pois não somos cativados para as referências passadas.

É nesse horizonte de discussão que envolve (res)sentimentos, experiências significativas, silêncios deliberados, filtragem de memória etc., que conduziremos nossa reflexão ${ }^{1}$. A intenção é dimensionar aspectos fenomenológicos e políticos da memória, centrados nas noções de intencionalidades, subjetividades, enquadramentos, ressentimentos e experiências como processos que também dialetizam o lembrar e o esquecer.

\section{Lembrança, transmissão e esquecimento}

A lembrança é capacidade de efetivação da memória, de recuperar algo do passado; ela escava na busca dos conteúdos da consciência e da experiência vivida subjetiva e coletivamente. Ela permite transmissão, capacidade do ser humano poder transcender-se, exteriorizar-se, dizer quem o mesmo foi ou correlacionar sua existência a algo externo e de significação. Sem transmissão, não deixaremos marcas e, são essas que nos identificam no tempo, nas coisas e na consciência das pessoas, nas linguagens, nos símbolos, nas imagens (GAGNEBIN, 1998). Porém, também, ao contrário, as lembranças podem nos fazer recordar de coisas, fatos e sentidos que gostaríamos de esquecer, ou que não nos são agradáveis. No fundo, 
ninguém gosta de ritualizar lembranças que quer esquecer, porém, autores colocam que o esquecimento, também, pressupõe rituais para apagá-lo.

A lembrança pressupõe situações de narrativas, força da transmissão para continuar a recordar e, com isso, a ativar a memória. Rituais, comemorações, fotografias, narrativas orais, imagens, objetos, museus, arquivos, saberes tradicionais, artesanatos, festas, rituais fúnebres etc., tudo isso auxilia nesse sentido; ambos/as estão envoltos/as nessas dimensões que produzem perdas, medo da morte, reconhecimento, identidade, busca por espaços etc.

Segundo Sarlo (2007), não há como não lembrar; propor-se a esquecer é como não perceber um cheiro, pois ambos são acometidos até mesmo quando não são esperados. "Justamente porque o tempo do passado não pode ser eliminado, e é um perseguidor que escraviza ou liberta, sua irrupção no presente é compreensível na medida em que seja organizado por procedimentos da narrativa" (SARLO, 2007, p. 12).

Rememorar pode significar retirar do esquecimento eventos marcantes, cuja importância considera-se fundamental para a subsistência, tanto do grupo, quanto de sua ética, como por exemplo, os genocídios dos armênios em 1915, os 500 anos da América ou do Brasil, os 60 anos do desembarque na Normandia, o 14 de julho para a França, o 4 de julho e o 11 de setembro nos EUA, os acordos de reparação de guerra em 1918 para a Alemanha..., enfim, são "operações de lembrança", que conseguem, pelos rituais e celebrações, fazer retornar à consciência histórica e grupal a presença de ocorrên- cias consideradas significativas (MARTINS, 2007, p. 39).

Alguns autores críticos da modernidade nos dizem que, no mundo atual, a memória não foi silenciada, mas desvirtuada (LEVI, 1986); foi dado a ela, e continua sendo, sentidos e conveniências. A mediação da narração foi fragilizada; não se trocam mais experiências (BENJAMIN, 1983); muitos se sentem ressentidos por não poderem se defender do passado considerado injusto e mal interpretado/explicado, por não poder intercambiar fatos, desejos de falar e acertar com o tempo e a História, de não poder se expor para dizer que sua experiência de vida e seu passado histórico não foram vazios ou prenhes de significados (TODOROV, 1995). Outros, então, poderão se ressentir por não encontrarem desejo, demanda e recepção de transmissão, de narração de seus vividos traumatizantes, como é o caso de ex-prisioneiros de campos de concentração que, ao serem libertos e depois de passar alguns anos do trauma (LEVI, 1986), não encontravam pessoas para ouvi-los e acreditar nas barbaridades cometidas nesses espaços, tudo isso em nome de um pacto do silêncio, como enquadramento social, produzido em determinados países da Comunidade Europeia, ou, então, como a Lei da Anistia no Brasil que exerceu um grande papel: o de esquecer e não permitir que sejam lembrados fatos e nem pessoas do período do governo militar; como é o caso em vários países onde houve ditaduras e foram cometidos genocídios e, agora, em décadas posteriores, governos democráticos não tomam providências para promover abertura de arquivos, nem mesmo de fossas onde se sabem que estão 
enterradas muitas pessoas, para, justamente, não mexer em feridas e não ferir acordos políticos (na Argentina, na Espanha, em Portugal, em países africanos, dentre outros, essa realidade é lugar comum).

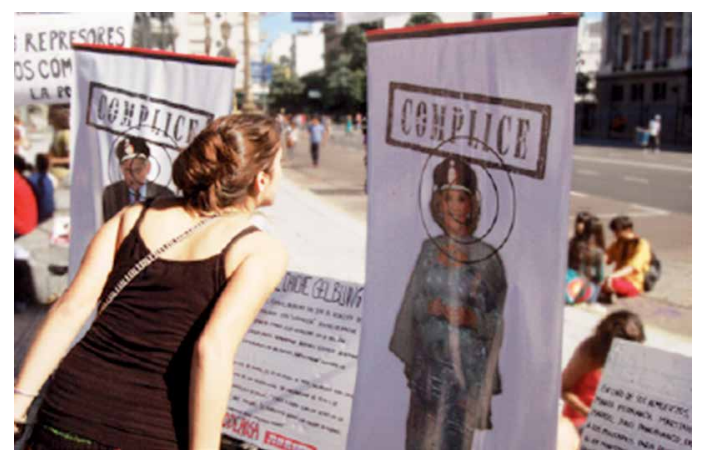

Fonte: http://operamundi.uol.com.br/conteudo/noticia/manifes tações+pro+contra+atual+governo+marcam+35+anive rsario+do+golpe+na+ Argentina_10722.shtml; acesso em 27/03/2011. Foto: Aldo Jofre Osorio.

Figura 1: Cartazes fazem um chamamento para que pessoas "cuspam sua raiva" em fotos de pessoas acusadas de cumplicidade com ditadores na Argentina; rituais públicos que marcaram os 35 anos do golpe no país, nos primeiros meses de 2011.

Os rituais de memória são importantes para impedir as perdas de memória, para não esquecermos (o) que vivemos, ou o que os outros fizeram (SARLO, 2007). No entanto, sabemos que tanto as lembranças quanto os esquecimentos, dependendo de seu conteúdo e uso que se faz, podem ser positivos e/ou negativos, traumáticos ou algo novo sobreposto. A memória coletiva pode ser induzida a esquecer e/ou a não ser justiciada pela lembrança, ou, então, por ações políticas, jurídicas e ideológicas do tempo presente e não necessariamente do tempo memorizado (TODOROV, 1995).

$O$ ressentimento pode se dar em torno do fato passado como também em torno da indiferença e não reconhecimento do presente para com o passado (BRESCIANI; NAXARA, 2004). Por isso que se diz que a memória é uma espécie de ruminante, mas que necessita de auxílio, desejo, apreensão, recepção de alguém para com outro alguém.

Não é incomum no meio social a produção do esquecimento ou do silêncio para ajustar o passado com as intenções/ressentimentos, ainda consequentes, do presente e das perspectivas futuras. Para Rossi (2010), a história e a vida pessoal fazem parte de um jogo, disputas essas em que há uma dialética entre revelação e encobrimento, manifestação e ocultação. Para o autor, o futuro dependerá da aceitação do passado. Porém, esse sempre foi, de vários modos, percebido, vivido, reconstruído, falsificado, restaurado, inventado, questionado, removido... Por isso que há várias maneiras de produzir e/ ou induzir ao esquecimento. Diz o mesmo que "apagar tem a ver com esconder, ocultar, despistar, confundir os vestígios, afastar da verdade, destruir a verdade" (IDEM, p. 32). Desse modo, há sempre certa coerção ao esquecimento, ao enquadramento de pensamentos, à necessidade de eliminar conteúdos de história ou a própria História, tenta-se também apagar os apagamentos, negar os fatos, dificultar a reconstrução de fatos, impedir que alguém possa lembrar (LEVI, 1986, p. 3). Diz Levi, de uma forma muito contundente e significativa, para quem viveu essa realidade de apagamento forçado que "ninguém de vocês viverá para dar testemunho; ainda que alguém escapasse, o mundo não acreditaria em vocês" (militares alemães falando para judeus em campos de concentração). Sobre esse apaga- 
mento e o sentimento de impotência frente à verdade de fatos bárbaros, Orwell (apud ROSSI, 2010, p. 34) descreve e projeta essa tendência e a importância de destruir e falsificar documentos, de deter a História, de que "não existe mais nada, exceto um presente sem fim"; ou seja, a dificuldade de ressurgir de um passado que foi apagado, da necessidade de apagamentos deliberados da memória, de produzir em seu lugar passados míticos. Afirma Levi (1986) que a história sempre necessitou de agentes do esquecimento e que servem aos poderes políticos, religiosos e culturais em especial. A atualidade expressa um grande "produtivismo arquivístico", muitos "ativistas da memória", "turistas da memória", como diz Nora em que muitas comemorações, monumentos se constituem num recurso e instrumento de ação política (é o caso dos debates e conflitos na decisão do Ground Zero, sobre o 11 de setembro nos EUA, bem como em torno do Memorial do Holocausto em 1993, do Vietnan Memorial nos Estados Unidos em 1982, bem como uma série de outros de grande expressão mundial) $)^{2}$.

As "batalhas de memória", as "autocelebrações", as "panes de memória", as "memórias hierarquizadas, as oficiais, subterrâneas e ocultadas" (genocídio de Ruanda em 1994, por exemplo, em que foram feitas mais de 800 mil vítimas em mais ou menos cem dias) oscilam entre o esquecimento e a lembrança. Ambos esses horizontes estão entranhados no campo político. O passado pode ser despótico e fossilizador do presente, bem como produzir transformações profundas na convivência social (TODOROV, 1995). Poderíamos nos perguntar como fez Can- dau (2005), se o esquecimento não seria uma forma de evitar os conflitos de memória? Se determinados monumentos poderiam servir de catarse? Se pacto de memória teria um efeito pacificador no interior de grupos confrontados em memórias conflituosas e dolorosas? Se a memória seria um entrave para a liberdade e a ação? Se o esquecimento produziria uma natureza emancipatória em sujeitos e grupos sociais? Se o esquecimento deliberado seria sempre causador de tragédias, ou se permitiria que pessoas ou pudessem construir e/ou restaurar uma imagem positiva de si? É interessante consentir o esquecimento, ou seja, "fazer passar o tempo"? Uma coisa é certa: as políticas de memória fazem parte de um jogo para decidir o que, quando, como, onde... lembrar, das modalidades de representação do passado.

Pollak (1989) fala que não é possível completa supressão de lembrança; o que existe é uma memória condicionada, reprimida, não enquadrada, não lembrada no coletivo histórico. Realidades negativas, vividas e acomodadas, funcionam como potencialidade, força de reserva, munição guardada para situações específicas do presente, principalmente no campo político e étnico.

Evitar falar, poupar alguém de ter a consciência de estar em meio a lembranças pouco edificantes, como é o caso, por exemplo, de memórias envergonhadas de uma família, de um sobrenome, de uma opção a um movimento histórico que ganhou ambivalência histórico-temporal como o nazismo, o fascismo, de uma empresa que faliu, de uma passagem familiar traumática etc., não é algo incomum no universo da memória, principalmente na sua dimensão histórica e 
cultural (SARLO, 2007). O que está em jogo, é a busca da eliminação do estigma da vergonha pela esfera do silêncio e da passagem do tempo. Há uma noção de temporalidade que se ordena com o "não dito" e se confia em seu esquecimento. Desse modo, ficamos com a consciência de que o que é esquecido não some, mas permanece no profundo a espera de ocasião adequada para sua desocultação (POLLAK, 1989).

Para Gadamer (1983, p. 38-39), esquecimento e lembrança não possuem limites definidos e nem definitivos; ao contrário, pode haver um diálogo, um entrecruzamento de apelos que acaba renovando e redefinindo a memória. Há uma dimensão política e deliberada do lembrar e do esquecer. Por isso que dominar esse processo é interessante para o campo do poder; controlar o esquecimento e a lembrança é um importante trunfo de quem governa (LE GOFF, 1979; KUNDERA, 1998). É bom que se diga que, com o passar do tempo, há ambivalências do esquecimento e da lembrança, em geral, como forma de salvaguardar memórias e identidades coletivas, ou, então, pelo desejo de expressão no futuro. Para Oliviero (1994), há sempre um certo equilíbrio entre lembrar e esquecer, entre as memórias que agregam e que estão na base da coesão social e as que são necessárias velar, esquecer ou deixar de lado, por serem desagregadoras, desagradáveis, traumáticas e ressentidas. Assim, memória e esquecimento não se anulam e nem se excluem, entrecruzam-se e podem até se compensar e se alimentar, mas tudo vai depender das circunstâncias sociais e temporais.
Recuperar fatos e coisas do passado pode-se tornar nostálgico demais, quando não melancólico (OLIVIERO, 1994), assim como cultuar e ritualizar memórias em demasia pode-se sacralizá-las, ou, então, torná-las impotentes e infrutíferas. $\mathrm{O}$ trabalho de luto (ritualizado), ou seja, vivenciar por algum tempo a realidade da perda, é uma das formas de se desangustiar, de acomodar o sentimento da perda e permitir a liberação da dominação da lembrança (TODOROV, 1995). É evidente que, por mais sofrível, incompreensível e indesejável que seja, o esquecimento possui uma função social, assim como a possui a memória como expressão de uma história comum, de garantir uma identidade coletiva, superando ressentimentos, os quais eternizam ódios e impedem a projeção no tempo, produzem tremendos e/ou potenciais conflitos sociais, fazem grupos, nações e indivíduos se armarem simbólica e efetivamente contra possíveis ataques ou ações de vingança (BRESCIANI; NAXARA, 2004).

Insistimos na ideia de que o ressentimento é uma forma de tornar a memória ativa. A culpa, a dívida, o rancor, a mágoa são ruminadores que ameaçam, exigem desforra, vingança, castigo, desejo de exorcizar a dívida, a má-consciência (NIETZSCHE, 1998). Isso permite "lavar a alma", produzir o esquecimento necessário e que permite ao organismo (psiqué) curar-se, dar lugar ao novo, à paz, à ordem psíquica harmônica e sadia (ROSSI, 2010). 


\section{Esquecer para lembrar e lembrar para}

\section{não esquecer}

O passado não pode ser inteiramente recordado e nem da mesma forma que foi vivido; a memória não tem essa capacidade de congelamento e cristalização, ou melhor, de ser um mero depósito, de resgate automático de tudo o que foi "colocado pra dentro". Lembrar algo significa colocar em evidência e/ou à parte determinados conteúdos. Essa é uma espécie de dialética da memória, necessária para dar o dinamismo que, tanto o esquecimento, quanto a recordação necessitam (BRESCIANI; NAXARA, 2004). Por isso Jedlowski (2000) diz que, em determinadas circunstâncias é interessante esquecer de ter esquecido alguma coisa. A consciência histórica se reconstrói sob um fundo de esquecimento; a mesma poderia se tornar infértil se mantivesse viva na memória a totalidade dos terríveis acontecimentos (ANSART, 2004).

Todorov (1995) insiste na dimensão ética da memória tanto em suas manifestações de lembranças quanto de esquecimentos, pois, de qualquer forma, ambos podem servir de exemplaridade, superação, modelos para construir o futuro e orientação (pedagógico) para o presente sem que haja uma obsessão desmesurada, tanto para um, quanto para outro. Por isso, haveria, em especial na esfera do poder, o uso político de ambos, por meio dos calendários oficiais, das festas, dos eventos necessários, dos tempos para a lembrança, na criação de monumentos em tempos e locais determinados etc. $\mathrm{Na}$ realidade, há necessidade de lembrar juntos, bem como de esquecer juntos (ELIAS, 1998), de criar uma seleção do senso comum, de pertencimentos, de recíproca conveniência reavivada por rituais linguísticos de conservação e de esquecimentos.
Cada povo, para saber viver, diz Todorov (1995), precisa saber recordar e saber esquecer. Porém, em geral, não gostamos de recordar o que nos machuca, os conteúdos dolorosos da memória. Contudo, também, sabemos que não podemos tudo esquecer, nem tudo lembrar; lembrar de algo significa escolher, selecionar, priorizar (BRESCIANI; NAXARA, 2004). A memória se presta para isso também; é como se houvesse uma racionalização da lembrança, um pragmatismo, um dever de recordar ou para superar, reelaborar, dramatizar, acordar com o passado, servir de guia para o presente (ANSART, 2004). Há vontades de memória e exteriorização que fazem parte das estratégias de produção e reprodução do tempo (tempos de homenagens, rituais de celebração, calendários oficiais, festejos etc.) que refletem situações de necessidade de recordação.

Rituais políticos de memória tendem a fazer reavivar contatos sociais, coletivos de uma forma deliberada. O poder político e de algumas outras instituições (família, religião, empresas) adotam critérios de referência que orientam a experiência do recordar e do esquecer em seus rituais linguísticos e narrativos ${ }^{3}$.

A história de nosso século, como sabemos bem, ainda quando buscamos esquecer, é cheia de censuras, cancelamentos, ocultamentos, desaparições, condenações, retrações públicas e confissões, traições, declarações de culpabilidade e de vergonha. Muitas obras históricas foram reescritas cancelando os nomes dos heróis de um tempo, catálogos editoriais foram mutilados, foram reeditados livros com conclusões diferentes daquelas originais... Primeiramente foram queimados livros, depois se fizeram desaparecer bibliotecas na tentativa de negar os fatos, de obstaculizar a reconstrução dos eventos, de impedir de contar as vítimas, de impedir as lembranças (ROSSI, 1991, p. 26). 
O trabalho de enquadramento de memória, ou seja, de fazer referência ao passado para manter a coesão grupal, para legitimar ações dos mesmos e/ou de instituições ou, então, para evitar oposições irredutíveis, define fronteiras grupais, possibilidades ou não de alteração pelos materiais que a História dispõe (ZAWADZKI, 2004).

Fatos históricos, dependendo das circunstâncias e conveniências, também podem passar pelo campo da ambiguidade e da incompreensão em torno de seus significados. Conchavos de hoje podem tornar-se conflitos de amanhã; ligações amistosas entre governos e países, de uma hora para outra, dependendo dos fatos, das pressões externas e públicas, podem também produzir conflitos. Governos e nações ressentem-se, produzem vínculos que começam a relembrar ou usar o passado como arma política. Essas realidades revelam que nem tudo se apaga, que a memória pode ser usada como arma política, que grupos sociais aliam-se e pactuam silêncios, muitas vezes, condicionados por acordos políticos de momentos.

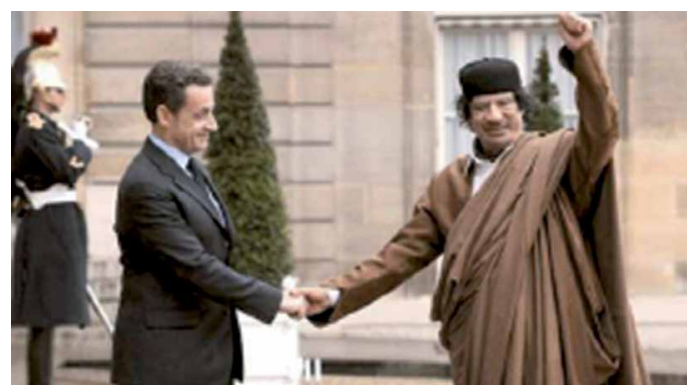

Fonte: <http://www.grandorient.org/Agencia/Noticias/Noticias. asp? ld=80 > . Acesso em: 27 mar. 2011. Foto: Redação da Agência Illumitati.

Figura 2: Presidente Sarkosi recebendo com honrarias o líder líbio Kadafi. Difícil imaginar que algum tempo depois desses encontros, Sarkosy passaria a ser peça-chave na coalizão internacional que promoveu o assassinato do líder líbio.
A experiência recalcada de fatos produtores de ódio pode ser causa de coesão e pertencimento, de desejos coletivos de vingança (queimar bandeiras de inimigos, apedrejar símbolos), uma espécie de fusão emocional que serve de maná, força, orgulho, expressos em sentimentos coletivos e/ ou individuais de desprezo, de desqualificação, quando não de um conflito aberto e ostensivo. O horizonte político (partidário e de nações) expressa muito bem isso (ZAWADZKI, 2004; ANSART, 2002). O ressentimento é um grande mobilizador coletivo. O que se questiona é a importância do ressentimento para o convívio social; ele seria necessário para não esquecer injustiças? Sabemos que ódios e ações de hostilidades manifestam-se de formas variadas nos tempos e nos grupos sociais (rivalidades vão sendo alimentadas e têm vida longa, seitas, representações e imaginários que vão se formando - antiamericanismo, antissemitas, antiestrangeiros, antimuçulmanos, anticiganos etc.) e podem, também, servir de arma política, causa de mobilização de grupos, ser uma ameaça pública, um temor simbólico que se alimenta no decorrer do tempo, renova-se com as conjunturas de oportunidades políticas e crises sociais e econômicas (ZAWADZKI, 2004; ANSART 2002).

Com isso tudo queremos dizer que a experiência em seus sentidos mais profundos é de difícil gerenciamento externo e interno; sentimentos não se apagam facilmente e nem se acomodam por determinadas ações de caráter apaziguador (ações afirmativas, perdão e reconhecimento público - como determinadas instituições o fazem tempos depois, a Igreja católica em especial 
[vide o caso Galileu, o caso do Nazismo na $2^{\text {a }}$ Guerra] -, legislação favorecedora aos trabalhadores como forma de acomodação social; políticas de compensação e responsabilidade social nas empresas etc.).

Enfim... O antônimo do esquecimento não é a memória, mas a justiça (Yerushalmi).

Horizontes invisíveis e não ditos não significam que não possuam existência, que não possam se revelar; há uma grande fronteira do conhecível no horizonte dos sentidos e da consciência do vivido humano e social. A correlação entre memória/lembrança e ressentimento nos diz isso muito bem. É importante termos presente que perceber esse sensível, muitas vezes inconsciente, é mostrar que possuímos zonas confusas e incertas em nosso agir social e experiência pessoal; essa dimensão pode estar impregnada também no campo político e produzir realidades de grande intensidade de adesão coletiva (ANSART, 2002). Vários autores analisaram a preparação de guerra da Alemanha nos anos 1930 e início dos anos 1940 como fruto de uma "guerra de memórias" (NAMER, 1983), de humilhações e desejos de vingança (aos judeus, aos franco-maçons), da revolta submissa, da passividade, da resignação e submissão à autoridade (ARENDT, 2002); da sede de vingança, do peso do passado, da infelicidade de sentir e não poder fazer nada (PORTELLI, 1995). Isso fez também passar de um sentimento a outro (de inferioridade para o de superioridade, sem limite, ideal de nacionalismo, “mitificação da coletividade" (ELIAS, 1998).
Por isso que o ressentimento pode ser um ato de "reparação" (ANGENOT, 1996), pois, segundo Namer (1983), pedir para as pessoas esquecerem, é fazer perpetuar a ferida, o perdão até pode amenizar a consequência, mas não produzir o apagamento. Exigir esquecimento é acabar com a autoestima, com a capacidade de reparação, é a resignação suprema (SILVA, 2010).

Insistimos no fato de que há uma produção também social dos ressentimentos, dos silêncios e das lembranças; revoltas, insurreições, linchamentos, terrorismos, queima de carros, invasões de terra, expatriamentos e expulsões de grupos étnicos (como as recentes ocorridas na França e na Itália com os ciganos [ROMs]), movimentos sociais de reparação e de promoção de justiça etc., podem ser alimentadas por ressentimentos. O sentimento ressentido por ser um antídoto e uma ação simbólica importantes no mundo atual para fazer frente à forte tendência de tudo esquecer rapidamente.

A dialética entre o esquecer e o lembrar está muito ligada ao ressentimento, aos ruminantes de memória; é parte da dinâmica social dos tempos e dos fatos, dos desejos e das potencialidades históricas da memória, dos significados que as pessoas e os grupos sociais e políticos dão ao passado. Por isso, dimensões subjetivas e políticas em torno da memória não podem ser negligenciadas.

\section{Abstract}

The text analyzes subjective horizons of memory and its political use; it shows that remembering and forgetting is something inseparable and indissoluble, 
they are interconnected; they may serve multiple functions and intentions. Forgetting can be deliberate, but also memories become selected. It will be given emphasis to the issue of individual and collective grievances demonstrating that there are feelings of memory which are deep, intense and difficult to erase. In this sense, both the remembrance and forgetfulness are dynamics that serve to adjust the past with the present.

Keywords: Memory. Resentment. Political power.

\section{Resumen}

El texto analiza horizontes subjetivos de la memoria bien como su uso político; demuestra que recuerdo y olvido son indisociables e indisolubles, están ligados entre sí; pueden servir para múltiples intenciones y funciones. Olvidos pueden ser deliberados, como también recuerdos pasan a ser seleccionados. Enfatizaremos a la cuestión de los resentimientos individuales y colectivos demostrando que hay sentimientos de memoria que son profundos, intensos y difíciles de borrar. En este sentido, tanto el recuerdo, cuanto el olvido son dinámicas que sirven para ayustar el pasado con el presente.

Palabras-clave: Memoria. Resentimiento. Poder Político.

\section{Notas}

1 As reflexões aqui desenvolvidas estão, de uma forma ou de outra, presente em nossos livros sobre memória; ver nas referências no final.

2 Um outro exemplo foi o demonstrado pelo programa da TVE espanhola - "Las fosas del olvido", em 28 de janeiro de 2004, revelando a existência de em torno de 800 fossas comuns contendo provavelmente $30 \mathrm{mil}$ republicanos mortos durante a guerra civil de meados do século XX no país. O programa fazia uma crítica ao governo socialista pelo fato de não "desenterrar os mortos", ou seja, de não fazer nada pelo temor de desestabilizar o pacto de convivência social produzido pós-conflito pelas várias forças. Depoimentos de grande expressão emotiva se fizeram presentes, bem como comentários em torno do fato de que os mortos "que estão lá", são os culpados hoje por uma possível desestabilização da democracia no país; antes os mesmos lutaram e foram mortos por ela (contra a política de repressão e autoritarismo do general Franco), agora eles são os culpados; ou seja, culpados são os que lutaram pela democracia e não os franchistas. A lembrança pública/oficial dos mortos altera a organização política e social dos vivos.

3 Ver BRESCIANI, S.; NAXARA, M. (Orgs.). Memória e (res)sentimento: indagações sobre uma questão sensível. Campinas: Unicamp, 2004. Os artigos do livro são importantes fontes, inauguraram uma temática importante e que, acreditamos, tende a crescer nos estudos sobre memória. Muito do que analisamos aqui tem como referência os seus estudos.

\section{Referências}

ANGENOT, M. Les ideologies du ressentiment. Montreal: XYZ Éditeurs, 1996.

ANSART, P. (Sous la direction de). Le ressentiment. Bruxelles: Bruylant, 2002.

. História e memória dos ressentimentos. In: BRESCIANI, S.; NAXARA, M. Memória e (res)sentimento: indagações sobre uma questão sensível. Campinas: Unicamp, 2004, p. 15-36.

ARENDT, H. Entre o passado e o futuro. São Paulo: Perspectiva, 2002. 
BENJAMIN, W. O narrador. In: Textos escolhidos: W. Benjamin, T. W. Adorno, J. Habermas. São Paulo: Abril Cultural, 1983. (Os Pensadores).

BRESCIANI, S.; NAXARA, M. Memória e (res) sentimento: indagações sobre uma questão sensível. Campinas: Unicamp, 2004.

CANDAU, J. Antrhopologie de la mémoire. Paris: Armand Colin, 2005.

ELIAS, N. Sobre o tempo. Rio de Janeiro: Zahar, 1998.

GADAMER, H. G. Verdade e método. Petrópolis: Vozes, 1983.

GAGNEBIN, J. M. Verdade e memória do Passado. Projeto História. São Paulo, 17, p. 213-221, 1998.

GALZERANI, M. B. Memória, história e tempo: perspectivas teórico-metodológicas para a pesquisa em ensino de história. Cadernos do Ceom. Chapecó, ano 21, n. 28, p. 15-30, 2008.

HUYSSEN, A. Seduzidos pela memória: arquitetura, monumentos, mídia. Rio de Janeiro, Aeroplano, 2000.

IZQUIERDO, I. Questões sobre memória. São Leopoldo: Editora Unisinos, 2004.

JEDLOWSKI, P. Storie comuni. La narrazione nella vita quotidiana. Milano: Mondadori, 2000.

KUNDERA, M. Il libro del riso e dell'oblio. Milano: Adelphi, 1998.

LE GOFF, J. Memoria. In: Enciclopedia, v. VIII, Torino: Einaudi, 1979. [Verbete].

LEVI. P. I sommersi e $i$ salvati. Turim: Einaudi, 1986.

MARTINS, E. C. de R. O enigma do passado: construção social da memória histórica. In: Textos de História. Revista do Programa de Pós-Graduação em História da UNB, v. 15, n. 1, p. 5-47, 2007.

NAMER, G. Batailles pour la mémoire. La commémoration em France, 1944-1982. Paris: Papyrus, 1983.

NIETZSCHE, F. Assim falou Zaratustra. Rio de Janeiro: Civilização Brasileira, 1998.
OLIVIERO, A. Ricordi individuali, memoria collettiva. Torino: Einaudi, 1994.

POLLAK, M. Memória, esquecimento, silêncio. Estudos Históricos. Rio de Janeiro, v. 2, n. 3, p. 3-15, 1989.

PORTELLI, A. A morte de Luigi Trastulli e outras histórias: forma e significado da história oral. São Paulo: PUC, 1995. Texto.

PROUST, M. Alla ricerca del tempo perduto. Torino: Einaudi, 1981.

ROSSI, P. Il passato, la memoria, l'oblio. Sei saggi di storia delle idee. Bologna: Il Mulino, 1991.

ROSSI, P. O passado, a memória, o esquecimento. Seis ensaios da história das ideias. São Paulo: Unesp, 2010.

SARLO, B. Tempo passado. Cultura da memória e guinada subjetiva. São Paulo: Companhia das Letras, 2007.

SILVA, P. R. da. Memória, história e cidadania. Revista Cadernos do CEOM, n. 32. Chapecó: Unochapecó, p. 327-346, 2010.

TEDESCO, J, C. Memória e cultura. Porto Alegre: EST, 2002.

TEDESCO, J. C. (Org.). Usos de memória: política, educação e identidade. Passo Fundo: UPF Editora, 2002.

. Nas cercanias da memória. Temporalidade, experiência e narração. Passo Fundo/Caxias do Sul: UPF Editora/UCS Editora, 2005.

Passado e presente em interfaces: introdução a uma análise sócio-histórica da memória. Passo Fundo/Chapecó/Porto Alegre: UPF Editora/Argos/Letra \& Vida, 2011.

TODOROV, T. Les abus de la mémoire. Paris: Arléa, 1995.

ZAWADZKI, P. O ressentimento e a igualdade: contribuição para uma antropologia filosófica da democracia. In. BRESCIANI, S.; NAXARA, M. Memória e (res)sentimento: indagações sobre uma questão sensível. Campinas: Unicamp, 2004, p. 371-401 